\title{
Development of glycerol-based metal-free carbon materials for environmental catalytic applications
}

\author{
Rui S. Ribeiro ${ }^{\mathrm{a}, \mathrm{b}}$, Adrián M.T. Silva ${ }^{\mathrm{b}}$, Maria T. Pinho ${ }^{\mathrm{b}}$, José L. Figueiredo ${ }^{\mathrm{b}}$, \\ Joaquim L. Faria ${ }^{\mathrm{b}}$, Helder T. Gomes ${ }^{\mathrm{a}, \mathrm{b}, *}$ \\ a Department of Chemical and Biological Technology, School of Technology and Management, Polytechnic Institute of Bragança, Campus de Santa Apolónia, \\ 5301-857 Bragança, Portugal \\ ${ }^{\mathrm{b}}$ LCM - Laboratory of Catalysis and Materials - Associate Laboratory LSRE/LCM, Faculdade de Engenharia, Universidade do Porto, Rua Dr. Roberto Frias, \\ 4200-465 Porto, Portugal
}

\section{A R T I C L E I N F O}

\section{Article history:}

Received 3 January 2014

Received in revised form 14 March 2014

Accepted 20 March 2014

Available online $\mathrm{xxx}$

\section{Keywords:}

Carbon material

Glycerol

Catalytic wet peroxide oxidation (CWPO)

Metal-free catalyst

2-Nitrophenol

\begin{abstract}
A B S T R A C T
A thermally stable and non-porous carbon material ( $S_{\mathrm{BET}}=10 \mathrm{~m}^{2} \mathrm{~g}^{-1}$ and no micropores), with low ash content and basic character, was produced by partial carbonization of glycerol with sulphuric acid followed by calcination under inert atmosphere. Further thermal activation in air atmosphere at different temperatures (from 150 to $350^{\circ} \mathrm{C}$ ) leads to materials with less basic character and to a tremendous evolution of the porosity, mostly microporosity $\left(S_{\mathrm{BET}}=598 \mathrm{~m}^{2} \mathrm{~g}^{-1}\right.$ and $\left.V_{\mathrm{Mic}}=0.24 \mathrm{~cm}^{3} \mathrm{~g}^{-1}\right)$. Experiments show that metal-free carbon materials synthesized by this approach can be highly active catalysts for the catalytic wet peroxide oxidation (CWPO) process when the surface chemistry and textural properties are adequately tuned. Effective catalytic degradation of 2 -nitrophenol ( $80 \%$ conversion) was achieved with the material treated under air atmosphere at $300^{\circ} \mathrm{C}$, even when operating under a high pollutant/catalyst mass ratio, opening a window of opportunity for added-value crude glycerol-derived products. Furthermore, catalyst activity was effectively recovered by a simple oxidative thermal regeneration procedure.
\end{abstract}

\section{Introduction}

Catalytic wet peroxide oxidation (CWPO) is an advanced oxidation process (AOP) characterized by the use of a suitable catalyst (typically an iron-based catalyst) for the decomposition of hydrogen peroxide $\left(\mathrm{H}_{2} \mathrm{O}_{2}\right)$ through the formation of hydroxyl radicals $\left(\mathrm{HO}^{\bullet}\right)$. These radicals exhibit high oxidizing potential and serve as effective species for the degradation of several organic pollutants in liquid phase, including those with a negative impact on conventional biological wastewater treatment plants [1].

CWPO is especially attractive due to the environmental safety of $\mathrm{H}_{2} \mathrm{O}_{2}$, mild operating conditions and simplicity of the equipment required [2]. Homogeneous and heterogeneous catalysts have been extensively used in this process for the degradation and mineralization of several organic pollutants in water (e.g., iron species used

\footnotetext{
* Corresponding author at: Department of Chemical and Biological Technology, School of Technology and Management, Polytechnic Institute of Bragança, Campus Santa Apolónia, 5301-857 Bragança, Portugal. Tel.: +351 273303 110; fax: +351273313051.

E-mail address: htgomes@ipb.pt (H.T. Gomes).
}

either directly in solution or immobilized on activated carbons) [3-6]. However, a complicated final chemically-driven separation step for the removal of the catalyst from the treated water is required when using homogeneous catalysts, while leaching of the active metal phase from the solid to the liquid phase is usually observed when heterogeneous catalysts are employed, thus resulting in catalyst deactivation [7].

Previously it has been shown that carbon materials (e.g. activated carbons and activated carbon xerogels), without any supported phase, are active catalysts for CWPO of water organic pollutants [8-12]. The development of metal-free catalysts for the CWPO process is of great interest in order to avoid leaching, deactivation and use of high-cost metals. On the other hand, crude glycerol, resulting from the biodiesel production process, is being offered as an abundant and low cost feedstock [13] and as the worldwide biodiesel production increases, so does the production of this by-product, making the new markets for crude glycerol a focus of attention [14].

In this work we developed glycerol-based carbon materials with distinct properties as catalysts for the CWPO process. 2-Nitrophenol (2-NP) was used as a non-biodegradable model pollutant. 


\section{Materials and methods}

\subsection{Carbon materials}

A glycerol-based carbon material was prepared by partial carbonization of glycerol (99 wt.\%), adapting the procedure described elsewhere [15]. Briefly, a mixture of glycerol (10 g) and concentrated (95-97 wt.\%) sulphuric acid ( $40 \mathrm{~g}$ ) was gently heated to $180^{\circ} \mathrm{C}$ and left at that temperature for $20 \mathrm{~min}$ to allow in situ partial carbonization. The resulting material, characterized as a strong solid acid carbon material, due to the presence of high amounts of sulphonic acid groups [15], was then ground to obtain particle sizes in the range $0.106-0.250 \mathrm{~mm}$ and further calcined under a nitrogen flow $\left(100 \mathrm{~cm}^{3} \mathrm{~min}^{-1}\right)$ at 120,400 and $600{ }^{\circ} \mathrm{C}$ during $60 \mathrm{~min}$ at each temperature, and then at $800^{\circ} \mathrm{C}$ for $240 \mathrm{~min}$, defining a heating ramp of $2{ }^{\circ} \mathrm{Cmin}^{-1}$, in order to stabilize the initial material (which by thermogravimetric analysis under nitrogen atmosphere revealed to decompose about $50 \mathrm{wt} . \%$ up to $800^{\circ} \mathrm{C}$ ). The as-calcined material was named GBCM and, as will be later observed in the characterization results, presents high thermal stability and basic character, which resulted from the decomposition of the sulphonic acid groups during the calcination procedure. Thereafter, GBCM was further thermally activated under oxidative atmosphere (air flow $=100 \mathrm{~cm}^{3} \mathrm{~min}^{-1}$ ) during $60 \mathrm{~min}$ at different temperatures, from $150^{\circ} \mathrm{C}$ to $350^{\circ} \mathrm{C}$, in order to produce several materials with different texture and surface chemistry, which were labelled as GBCM followed by a subscript number corresponding to the activation temperature in ${ }^{\circ} \mathrm{C}$ (i.e., $\mathrm{GBCM}_{150}, \mathrm{GBCM}_{200}, \mathrm{GBCM}_{300}$ and $\mathrm{GBCM}_{350}$ ). In this temperature range, the weight loss (burn-off) due to the thermal activation under air atmosphere ranges from 9 wt.\% to 20 wt.\%.

\subsection{Characterization techniques}

Textural characterization was performed in a Quantachrome NOVA 4200e adsorption analyser. Thermogravimetric analysis (TGA) was performed using a Netzsch STA 409 PC equipment. Scanning electron microscopy (SEM) images were obtained using a FEI Quanta 400FEG ESEM/EDAX Genesis X4M instrument equipped with an Energy Dispersive Spectrometer (EDS). The surface chemistry of the carbon materials was characterized as described elsewhere [8], namely by (i) the $\mathrm{pH}$ of point of zero charge $\left(\mathrm{pH}_{P Z C}\right)$, determined by $\mathrm{pH}$ drift tests, (ii) the concentration of acidic and basic sites, using titration techniques, and (iii) the amounts of $\mathrm{CO}_{2}$, $\mathrm{CO}$ and $\mathrm{SO}_{2}$ released from the materials surface by temperature programmed desorption (TPD) analysis. Elemental analysis was performed in a Carlo Erba EA 1108 Elemental Analyser.

\subsection{2-Nitrophenol removal experiments}

Batch pure adsorption and CWPO experiments were performed in a $500 \mathrm{~mL}$ well-stirred $(600 \mathrm{rpm})$ glass reactor, equipped with a condenser, a temperature measurement thermocouple, a $\mathrm{pH}$ measurement electrode and a sample collection port. The reactor was loaded with $250 \mathrm{~mL}$ of a 2-NP aqueous solution and heated by immersion in an oil bath at controlled temperature. Upon stabilization at $50^{\circ} \mathrm{C}$, the solution $\mathrm{pH}$ was adjusted to 3 , by means of $\mathrm{H}_{2} \mathrm{SO}_{4}$ and $\mathrm{NaOH}$ solutions, and the experiments were allowed to proceed freely, without further conditioning the $\mathrm{pH}$. Screening experiments were conducted during $4 \mathrm{~h}$, at $T=50^{\circ} \mathrm{C}$, $\mathrm{pH}=3,[2-\mathrm{NP}]_{0}=0.1 \mathrm{~g} \mathrm{~L}^{-1}$, adsorbent $/$ catalyst load $=1.0 \mathrm{~g} \mathrm{~L}^{-1}$ (corresponding to a $2-\mathrm{NP} /$ catalyst mass ratio $=0.1$ ) and, following the conditions used in the works recently developed by our group $[8,9,16,17]$, a calculated volume of $\mathrm{H}_{2} \mathrm{O}_{2}(6 \% \mathrm{w} / \mathrm{v})$ was injected into the system before catalyst addition in order to reach a concentration of $34.6 \mathrm{mmol} \mathrm{L}^{-1}$ in the CWPO runs (three times the

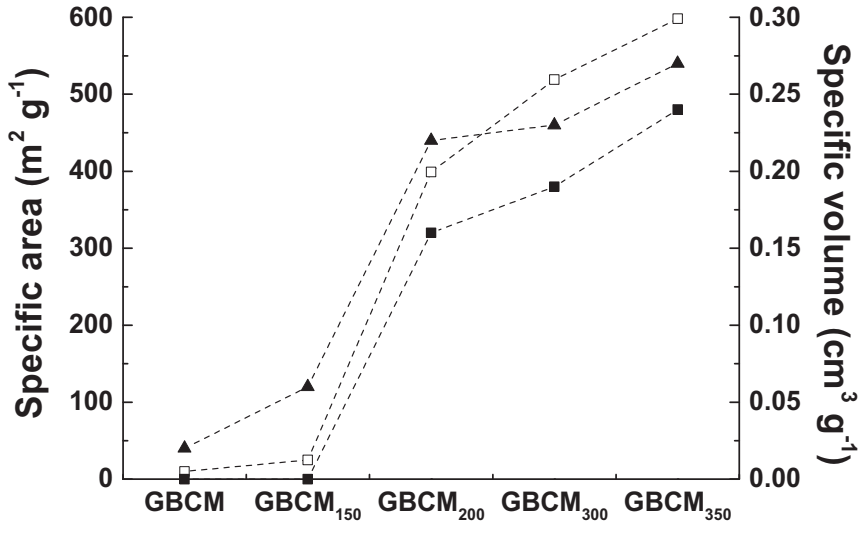

Fig. 1. Specific surface area $\left[S_{\mathrm{BET}}(\square)\right.$, left axis], micropore volume $\left[V_{\mathrm{Mic}}(\boldsymbol{\square})\right.$, right axis] and total pore volume $\left[V_{\text {Total }}(\boldsymbol{\Lambda})\right.$, right axis] of the carbon materials.

stoichiometric amount needed to completely mineralize 2-NP). Process intensification experiments were conducted during $24 \mathrm{~h}$ considering $[2-\mathrm{NP}]_{0}=0.5 \mathrm{~g} \mathrm{~L}^{-1}$, adsorbent $/$ catalyst load $=0.25 \mathrm{~g} \mathrm{~L}^{-1}$ (corresponding to a $2-\mathrm{NP} /$ catalyst mass ratio $=2$ ) and the stoichiometric amount of $\mathrm{H}_{2} \mathrm{O}_{2}$ needed to completely mineralize 2-NP $\left(52.2 \mathrm{mmol} \mathrm{L}^{-1}\right)$. Blank experiments, without any catalyst, were carried out in both cases to assess possible non-catalytic oxidation promoted by $\mathrm{H}_{2} \mathrm{O}_{2}$.

\subsection{Analytical methods}

2-NP concentration was determined by high performance liquid chromatography (HPLC), as described elsewhere [17]. In the samples collected from CWPO runs, an excess of sodium sulphite was immediately added to consume residual $\mathrm{H}_{2} \mathrm{O}_{2}$ and to instantaneously stop the reaction [18]. Total organic carbon (TOC) was determined using a Shimadzu TOC-5000A analyser. The concentration of $\mathrm{H}_{2} \mathrm{O}_{2}$ was followed by a colorimetric method, as described elsewhere [19].

\section{Results and discussion}

\subsection{Textural and surface chemistry characterization}

The TGA analysis performed under $\mathrm{N}_{2}$ atmosphere (not shown), upon heating the GBCM sample from 25 to $900^{\circ} \mathrm{C}$ at $25^{\circ} \mathrm{C} \mathrm{min}^{-1}$, reveals $3.1 \mathrm{wt} . \%$ of volatiles, indicating that the material is thermally stable up to $900^{\circ} \mathrm{C}$ under inert atmosphere. On the other hand, by TGA analysis under air atmosphere (not shown), it was found that the GBCM sample is stable up to $400^{\circ} \mathrm{C}$ under oxidizing atmosphere. A very low ash content (1.1 wt.\%) was also quantified.

The effects of the different thermal treatments on the textural properties of the carbon materials, calculated from the $\mathrm{N}_{2}$ adsorption isotherms (not shown), are presented in Fig. 1.

The original GBCM is a non-porous material $\left(V_{\text {Total }}=0.02 \mathrm{~cm}^{3} \mathrm{~g}^{-1}\right.$ and $\left.S_{\mathrm{BET}}=10 \mathrm{~m}^{2} \mathrm{~g}^{-1}\right)$ and the thermal activation of GBCM in air atmosphere leads to a considerable generation of porosity in the resulting materials, the $S_{\mathrm{BET}}$ increasing with the temperature applied $\left(25,399,519\right.$ and $598 \mathrm{~m}^{2} \mathrm{~g}^{-1}$ at $150,200,300$ and $350^{\circ} \mathrm{C}$, respectively), as well as the $V_{\text {Mic }}$ $\left(0.00,0.16,0.19\right.$ and $0.24 \mathrm{~cm}^{3} \mathrm{~g}^{-1}$, respectively). Higher activation temperatures lead to a significant development of microporosity. In fact, thermal activation of GBCM in air atmosphere at $350^{\circ} \mathrm{C}$ leads to a tremendous evolution of porosity (about 60 -fold in $S_{\text {BET }}$ and 13.5-fold in $V_{\text {Total }}$ ), resulting a material with a microporosity fraction $\left(V_{\text {Mic }} / V_{\text {Total }}=0.90\right)$ close to that reported for some activated carbons and carbon xerogels $[9,20]$. This development of 

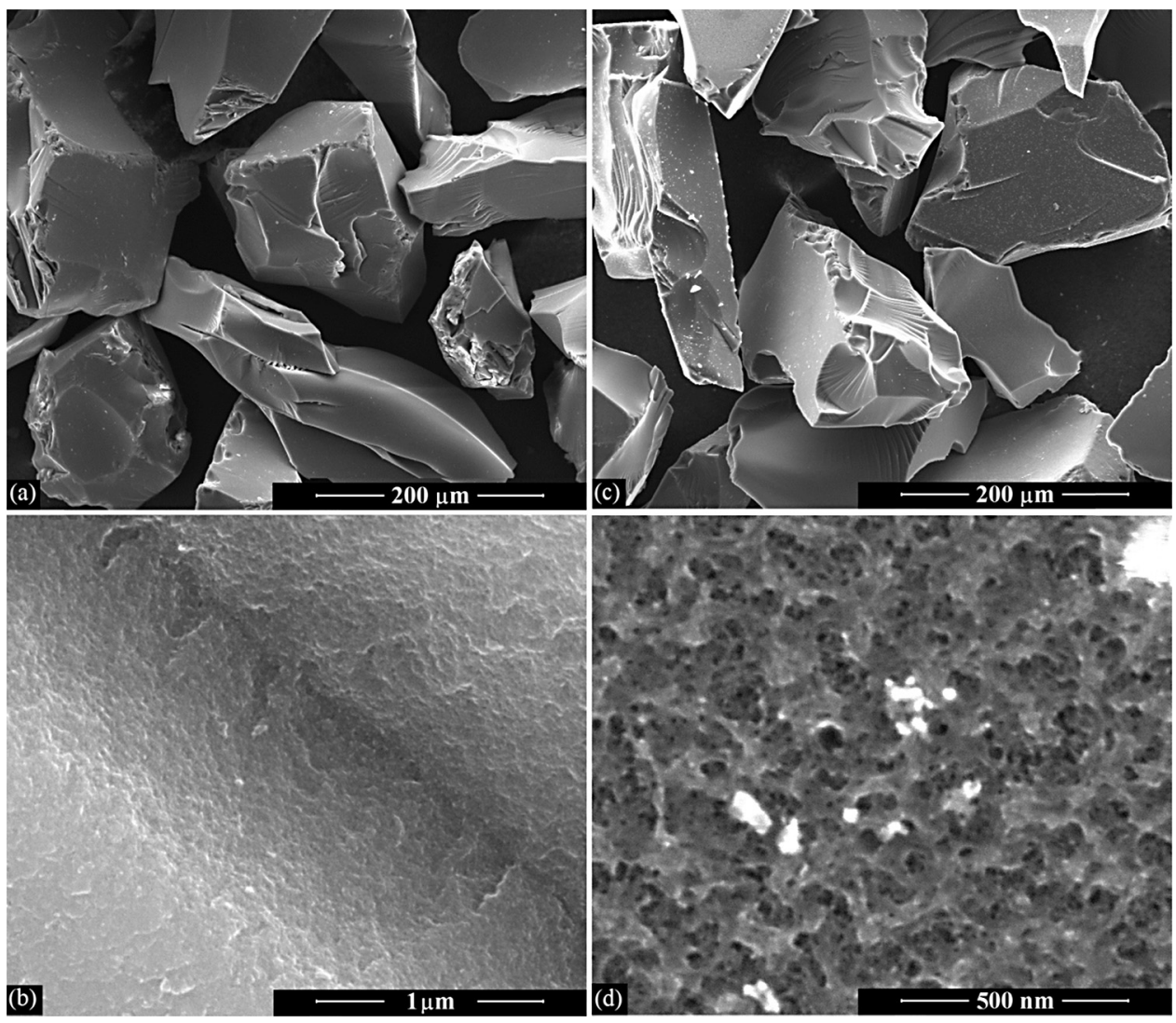

Fig. 2. SEM micrographs of (a) and (b) GBCM and (c) and (d) $G B C M_{300}$.

porosity, mostly within micropores, obtained through activation in air atmosphere, is clearly visible by SEM, as shown in Fig. 2.

The surface chemical properties of the carbon materials were also determined, the corresponding values being summarized in Table 1 . The basic character of the original GBCM is evident, with a concentration of basic functionalities higher than the concentration of acidic functionalities and a $\mathrm{pH}_{P Z C}$ of 9.5. As the activation temperature increases, the amount of acidic functionalities of the resulting materials also increases, with a markedly acidic material $\left(\mathrm{pH}_{P Z C}=2.6\right)$ being obtained at $350^{\circ} \mathrm{C}$. As expected, this evolution is followed by the increase of oxygen-containing groups released during TPD analysis ( $c f$. Fig. 3 and Table 1), particularly for temperatures above $200^{\circ} \mathrm{C}$, suggesting that the increase of acid functionalities is due to the incorporation of surface oxygen groups during thermal activation in air atmosphere [21].

In order to identify and quantify the amounts of the different functional groups originally present at the surface of GBCM and/or introduced during thermal activation under an oxidative atmosphere of air, a deconvolution analysis of the $\mathrm{CO}_{2}$ and CO TPD spectra was performed as previously described [21]. For this purpose, the peaks in the $\mathrm{CO}_{2}$ TPD spectra of the carbon materials were assigned to different functional groups, namely: (I) carboxylic acids (released in the range $230-350^{\circ} \mathrm{C}$ ), (II) carboxylic anhydrides $\left(480-540^{\circ} \mathrm{C}\right)$ and (III) lactones $\left(610-720^{\circ} \mathrm{C}\right)$. Likewise, the peaks in the CO TPD spectra were assigned to (II) carboxylic anhydrides $\left(480-540^{\circ} \mathrm{C}\right),(\mathrm{IV})$ phenols $\left(640-670^{\circ} \mathrm{C}\right),(\mathrm{V})$ ethers $\left(700-720^{\circ} \mathrm{C}\right)$ and $(\mathrm{VI})$ quinones $\left(820-850^{\circ} \mathrm{C}\right)$, as illustrated in the deconvolution of the $\mathrm{CO}_{2}$ and $\mathrm{CO}$ peaks of $\mathrm{GBCM}_{300}$ shown in Fig. 4. The amounts of the functional groups present at the surface of the different carbon materials produced are presented in Table 2. From these results it can be concluded that the increase of oxygen-containing groups previously commented ( $c f$. Fig. 3 and Table 1 ) is mainly due to the incorporation of lactones, phenols and quinones.
In addition to the TPD results, elemental and EDS analyses confirmed that the carbon materials produced from glycerol are mainly composed of carbon and oxygen, with some residual sulphur in the composition. By TPD analysis we were not able to identify the nature of possible sulphur containing functional groups, since no detectable signal was attributed to the release of $\mathrm{SO}_{2}$ (normally associated with the decomposition of sulphonic acid groups or with other sulphur-containing functionalities [16]). However, since the increase of the acidity of the materials activated at higher temperatures cannot be fully explained by the incorporation of lactones, phenols and quinones, it should be reasonable to expect that some acidic functionalities (not detected by TPD) may be present in the surface of the materials.

\subsection{CWPO experiments}

The ability of the carbon materials produced from glycerol to act as metal-free catalysts in the CWPO of 2-NP was evaluated through screening experiments performed under the conditions referred in to Section 2.3. The removals of 2-NP obtained by pure adsorption and by CWPO in the presence of GBCMs, after $2 \mathrm{~h}$ and $4 \mathrm{~h}$, are given in Fig. 5(a) and (b). The main conclusion withdrawn from this set of results is that catalytic activity is unequivocally obtained for carbon materials produced from glycerol. After appropriate activation conditions of the parent material, a marked increase of the 2-NP removal in the CWPO experiments compared to the pure adsorption experiments $\left(d_{\text {Removal }}\right)$ is observed in the presence of some of the produced GBCMs materials and, in particular, for the material treated under air atmosphere at $300^{\circ} \mathrm{C}$.

In fact, the difference of 2-NP removal due to $\mathrm{H}_{2} \mathrm{O}_{2}$ addition goes through a maximum (Fig. 5), corresponding to a superior performance of $\mathrm{GBCM}_{300}, 5$-fold (after $2 \mathrm{~h}$ ) and 2-fold (after $4 \mathrm{~h}$ ) when compared to the performance of the non-activated GBCM. 
Table 1

Properties of the carbon materials: $\mathrm{pH}_{P Z C}$, acid-base properties, amounts of $\mathrm{CO}_{2}$ and $\mathrm{CO}$ and percentage of oxygen obtained from the TPD spectra of the carbon materials.

\begin{tabular}{|c|c|c|c|c|c|c|}
\hline \multirow[t]{2}{*}{ Material } & \multicolumn{6}{|c|}{ Parameter } \\
\hline & $\mathrm{pH}_{P Z C}$ & Acidity $\left(\mu \mathrm{mol} \mathrm{g}^{-1}\right)$ & Basicity $\left(\mu \mathrm{mol} \mathrm{g}^{-1}\right)$ & $\mathrm{CO}_{2}\left(\mu \mathrm{molg}^{-1}\right)$ & $\mathrm{CO}\left(\mu \mathrm{molg}^{-1}\right)$ & $\mathrm{O}(\%)$ \\
\hline GBCM & 9.5 & 380 & 590 & 213 & 395 & 1.3 \\
\hline $\mathrm{GBCM}_{150}$ & 9.2 & 270 & 450 & 255 & 572 & 1.7 \\
\hline $\mathrm{GBCM}_{200}$ & 7.6 & 310 & 500 & 524 & 940 & 3.2 \\
\hline $\mathrm{GBCM}_{300}$ & 6.2 & 520 & 400 & 663 & 2843 & 6.7 \\
\hline $\mathrm{GBCM}_{350}$ & 2.6 & 1250 & 250 & 955 & 3482 & 8.6 \\
\hline
\end{tabular}

Table 2

Deconvolution of the TPD spectra using a multiple Gaussian function.

\begin{tabular}{|c|c|c|c|c|c|c|}
\hline \multirow[t]{2}{*}{ Material } & \multicolumn{2}{|l|}{$\mathrm{CO}_{2}$} & \multirow{2}{*}{$\begin{array}{l}\mathrm{CO}_{2} \text { and } \mathrm{CO} \\
\text { Anhydrides }\left(\mu \mathrm{molg}^{-1}\right)\end{array}$} & \multicolumn{3}{|l|}{$\mathrm{CO}$} \\
\hline & Carboxylic $\left(\mu \mathrm{molg}^{-1}\right)$ & Lactones $\left(\mu \mathrm{mol} \mathrm{g}^{-1}\right)$ & & Phenols $\left(\mu \mathrm{molg}^{-1}\right)$ & Ethers $\left(\mu \mathrm{mol} \mathrm{g}^{-1}\right)$ & Quinones $\left(\mu \mathrm{mol} \mathrm{g}^{-1}\right)$ \\
\hline GBCM & 66 & 48 & 72 & 0 & 100 & 176 \\
\hline $\mathrm{GBCM}_{150}$ & 110 & 72 & 53 & 152 & 12 & 332 \\
\hline $\mathrm{GBCM}_{200}$ & 220 & 225 & 53 & 298 & 20 & 482 \\
\hline $\mathrm{GBCM}_{300}$ & 17 & 514 & 104 & 1391 & 70 & 1207 \\
\hline $\mathrm{GBCM}_{350}$ & 0 & 762 & 164 & 1941 & 123 & 1132 \\
\hline
\end{tabular}

The highest removal of 2-NP is observed when using $\mathrm{GBCM}_{350}$ but, in this case, pure adsorption experiments may indicate that significant adsorption of 2-NP occurs on the surface of this carbon material, reason why $\mathrm{GBCM}_{300}$ was selected for further process intensification, reutilization and regeneration studies. In either case, it can be observed that very active catalysts can be produced from glycerol by selecting the proper temperature for the oxidative treatment under air atmosphere $\left(300^{\circ} \mathrm{C}\right.$ in the present study), a
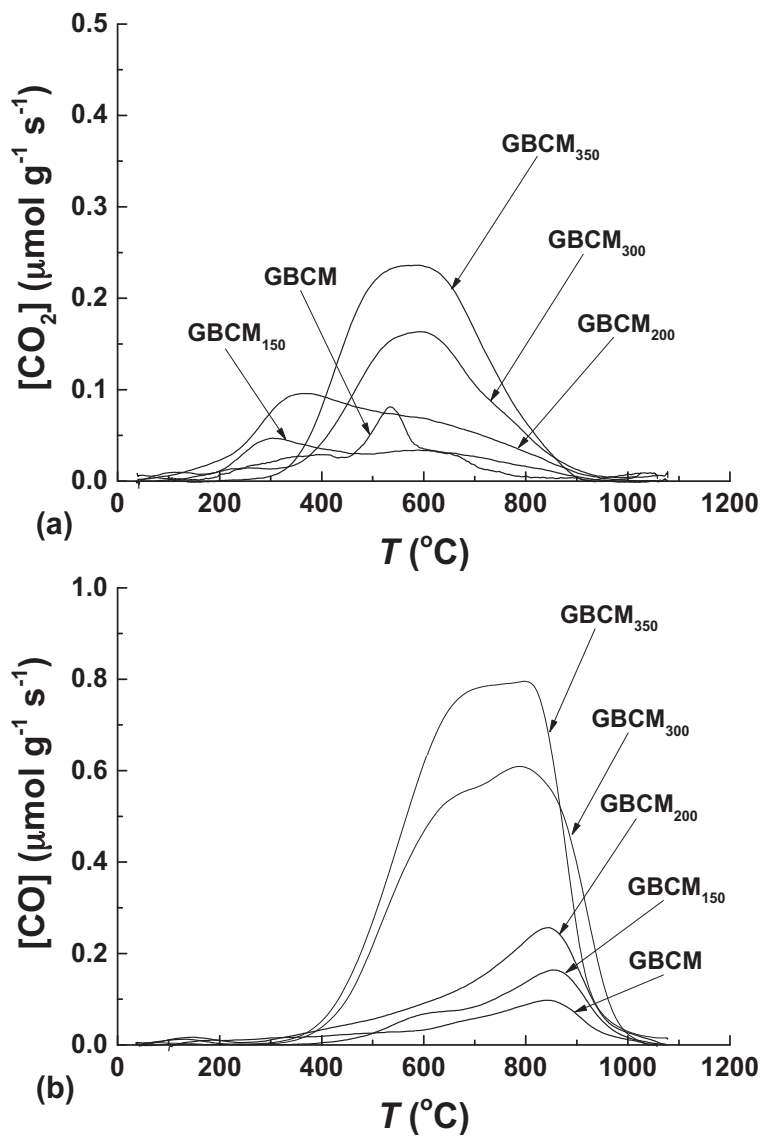

Fig. 3. TPD spectra of the carbon materials: (a) $\mathrm{CO}_{2}$ and (b) $\mathrm{CO}$ evolution with temperature. methodology that allows the control of the textural and surface chemical properties of the carbon material.

Taking into account (i) that the experiments were performed at $\mathrm{pH}=3$, (ii) the acid dissociation constant of $2-\mathrm{NP}(\mathrm{pKa}=7.2$, thus found in solution predominantly in the molecular form) and (iii) the $\mathrm{pH}_{P Z C}$ of the materials, it can be concluded that electrostatic interactions between the surface of the carbon materials and the 2-NP molecules cannot be the main driving force to explain the
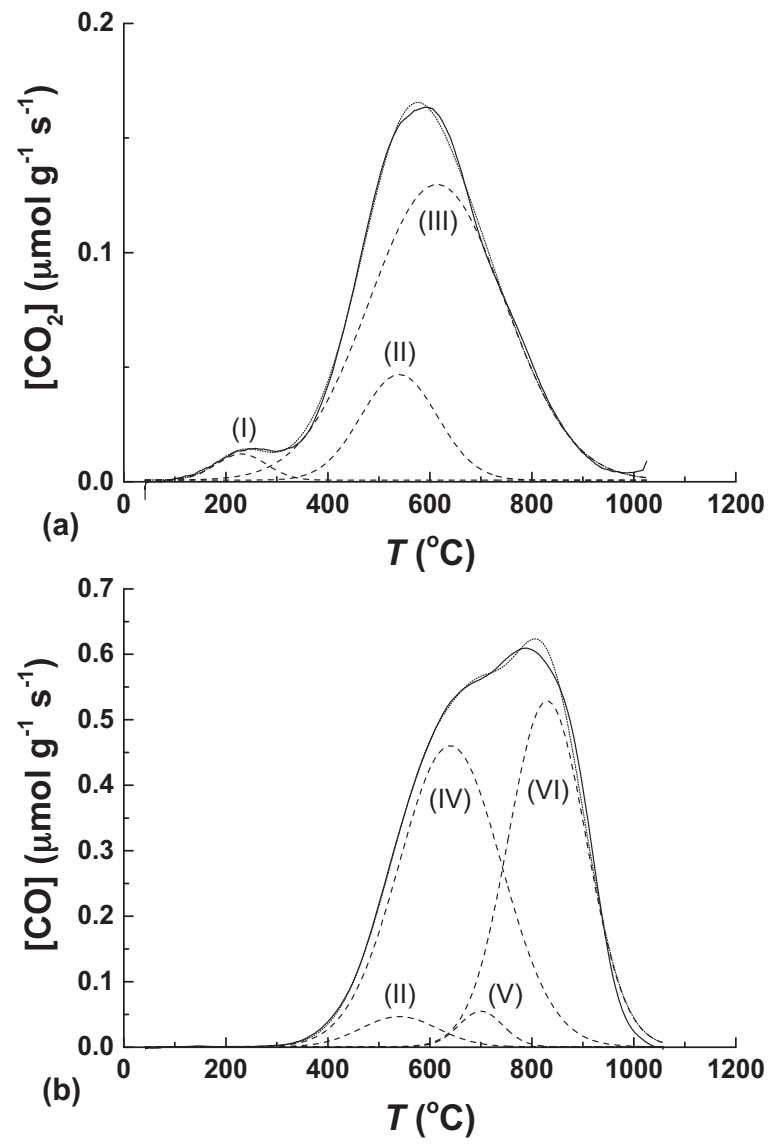

Fig. 4. Deconvolution results of (a) $\mathrm{CO}_{2}$ and (b) $\mathrm{CO}$ TPD spectra of $\mathrm{GBCM}_{300}$ using a multiple Gaussian function (dashed lines). Peaks denoted as I-VI are assigned to carboxylic acids, carboxylic anhydrides, lactones, phenols, ethers and quinones respectively. 

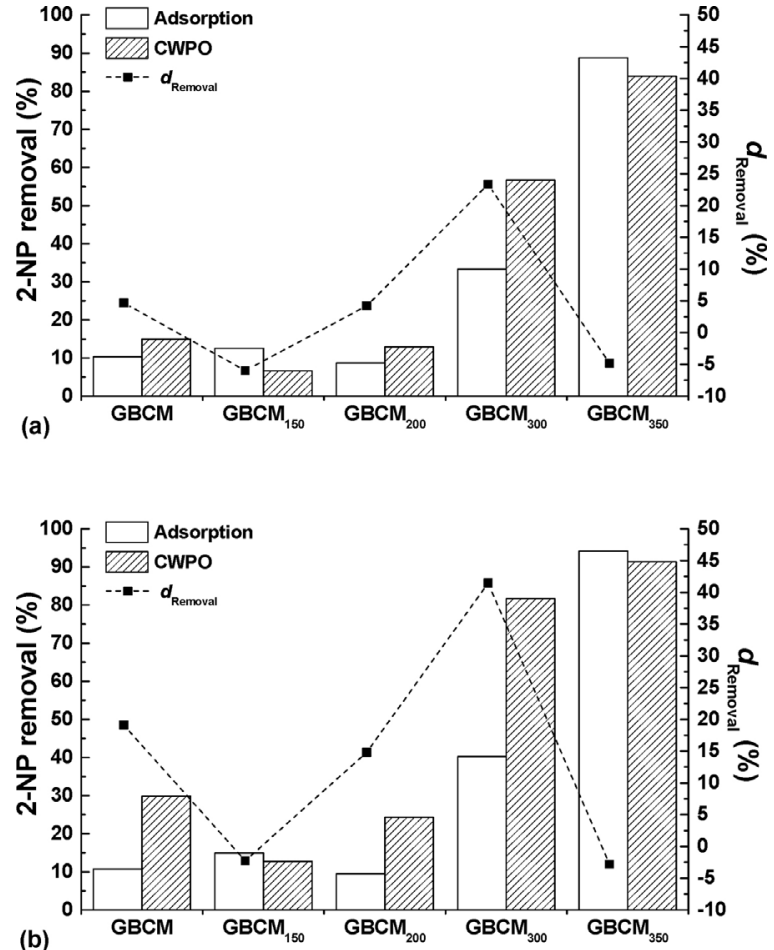

Fig. 5. 2-NP removal in adsorption and CWPO runs (bars/left axis) after (a) $2 \mathrm{~h}$ and (b) $4 \mathrm{~h}$, and respective difference due to $\mathrm{H}_{2} \mathrm{O}_{2}$ addition [ $d_{\text {Removal }}$ (squares/right axis)].

different adsorption behaviour of the materials [22,23]. Considering the specific surface areas, the carbon material with the most developed porous structure (i.e., $\mathrm{GBCM}_{350}$, with $S_{\mathrm{BET}}=598 \mathrm{~m}^{2} \mathrm{~g}^{-1}$ ) would be expected to show the best adsorption performance, which is confirmed by the adsorption results obtained.

CWPO is a much more complex process than pure adsorption. Several authors reported carbon materials with basic character as more active for $\mathrm{H}_{2} \mathrm{O}_{2}$ decomposition in CWPO processes $[12,19,24,25]$ and that oxygen-containing functionalities existing on the surface of a catalyst, having an electron withdrawal capacity, limit the catalytic performance of the material $[19,25,26]$. As observed, the material that better combines all of these properties is in fact $\mathrm{GBCM}_{300}$, which shows the best catalytic activity in the removal of 2-NP by CWPO. This material possesses an interesting development of porosity $\left(S_{\mathrm{BET}}=519 \mathrm{~m}^{2} \mathrm{~g}^{-1}, S_{\text {Non-mic }}=61 \mathrm{~m}^{2} \mathrm{~g}^{-1}\right.$, $\left.V_{\text {Mic }}=0.19 \mathrm{~cm}^{3} \mathrm{~g}^{-1}\right)$, enabling the adsorption of the organic pollutant at its surface, and a basicity of $400 \mu \mathrm{mol} \mathrm{g}^{-1}$ (almost 2-fold higher than that of $\mathrm{GBCM}_{350}$ ), which combined with an inferior oxygen content (6.7\%) leads to higher activation of $\mathrm{H}_{2} \mathrm{O}_{2}$ molecules in close proximity of the 2-NP molecules. Hereupon, it is concluded that a balance between the textural and chemical properties is crucial in the synthesis of highly active catalysts for the CWPO process.

Materials activated at lower temperatures have an important basic character (basicity $>450 \mu \mathrm{mol} \mathrm{g}^{-1}$ ), with a lower oxygen content $(<3.2 \%)$, but also a very poor porous structure, while the material activated at the highest temperature $\left(350^{\circ} \mathrm{C}\right)$ has a significant porosity, but a very high oxygen content (8.6\%), combined with a low basicity $\left(250 \mu \mathrm{mol} \mathrm{g}^{-1}\right)$.

\subsection{Process intensification}

In order to assess the ability of $\mathrm{GBCM}_{300}$ to act as catalyst in CWPO processes under intensified conditions, which may be potentially more attractive for industrial applications (i.e., to treat wastewaters with higher pollutant concentrations using lower catalyst and $\mathrm{H}_{2} \mathrm{O}_{2}$ consumptions per mass of pollutant, thus increasing

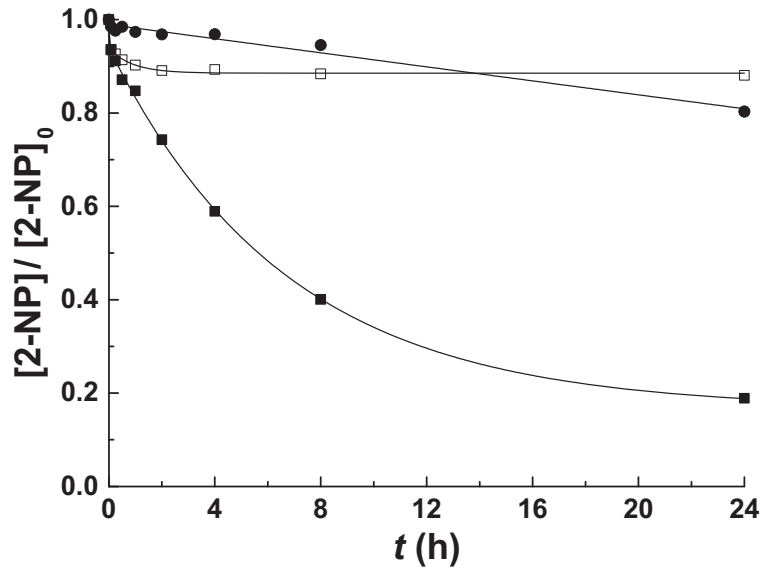

Fig. 6. Removal of 2-NP $\left(0.5 \mathrm{~g} \mathrm{~L}^{-1}\right)$ obtained in adsorption ( $\left.\square\right)$ and CWPO ( $\left.\mathbf{\square}\right)$ runs performed with $\mathrm{GBCM}_{300}\left(0.25 \mathrm{~g} \mathrm{~L}^{-1}\right)$, considering $\left[\mathrm{H}_{2} \mathrm{O}_{2}\right]_{0}=52.2 \mathrm{mmol} \mathrm{L}^{-1}$ (stoichiometric amount needed to completely mineralize 2-NP), $T=50^{\circ} \mathrm{C}$ and $\mathrm{pH}=3$. Non-catalytic results with $\mathrm{H}_{2} \mathrm{O}_{2}(\bullet)$ are also shown for comparison.

the efficiency of the catalyst and $\mathrm{H}_{2} \mathrm{O}_{2}$ usage), the 2-NP concentration was increased to $0.5 \mathrm{~g} \mathrm{~L}^{-1}$, the $\mathrm{GBCM}_{300}$ load was decreased to $0.25 \mathrm{~g} \mathrm{~L}^{-1}$, and the dosage of $\mathrm{H}_{2} \mathrm{O}_{2}$ in the CWPO process was lowered to the stoichiometric amount needed to completely mineralize 2-NP.

The 2-NP removals obtained as a function of time in adsorption and CWPO runs performed during $24 \mathrm{~h}$ with $\mathrm{GBCM}_{300}$ in these intensified operating conditions, together with the non-catalytic removal obtained in the same operating conditions, are collected in Fig. 6. It is clearly seen that the contributions of pure adsorption and non-catalytic removals are substantially lower than the 2-NP removal obtained by CWPO, the adsorption of 2-NP mainly taking place during the first $30 \mathrm{~min}$ of the experiment. Furthermore, the initial removal rate of 2-NP by CWPO under the intensified conditions, $102.6 \mathrm{mg} \mathrm{g}_{\mathrm{cat}^{-1}} \mathrm{~min}^{-1}$, is strongly increased (13-fold higher) when compared to the initial removal rate of $2-\mathrm{NP}$ obtained after $4 \mathrm{~h}$ of reaction under the screening conditions $\left(7.86 \mathrm{mg} \mathrm{g}_{\mathrm{cat}}{ }^{-1} \mathrm{~min}^{-1}\right)$.

These observations lead to the conclusion that the efficiency of the $\mathrm{GBCM}_{300}$ catalyst is clearly increased when the CWPO process is implemented under intensified conditions.

In order to access the stability of $\mathrm{GBCM}_{300}$ - a basic requirement for industrial scale applications - this catalyst was tested in a series of three consecutive CWPO runs. For that purpose, after each run, the catalyst was filtered, washed and dried at $60^{\circ} \mathrm{C}$ overnight, and then reused in CWPO with a fresh 2-NP solution. The 2-NP and TOC removals, as well as the corresponding $\mathrm{H}_{2} \mathrm{O}_{2}$ decomposition obtained after $24 \mathrm{~h}$ of reaction in this series of experiments are given in Fig. 7.

As observed, the 2-NP and TOC removals obtained in the first run are higher when compared to the removals observed in the second run. This phenomenon was somehow expected due to the contribution of adsorption in the first use of the catalyst. However, a closer analysis reveals that adsorption, only by itself, is not enough to justify the difference between the 2-NP removals observed in the first and in the second runs. In fact, as recently shown in the CWPO of phenol over microporous activated carbon catalysts [11], this decrease of the catalytic activity of $\mathrm{GBCM}_{300}$ may also be explained by deactivation of the carbon active sites responsible for hydrogen peroxide decomposition into $\mathrm{HO}^{\bullet}$, due to reduction of the specific surface area caused by 2-NP reaction by-products adsorbed or deposited on the carbon surface $\left(S_{\mathrm{BET}}=180 \mathrm{~m}^{2} \mathrm{~g}^{-1}, V_{\mathrm{Mic}}=0.04 \mathrm{~cm}^{3} \mathrm{~g}^{-1}, V_{\text {Total }}=0.10 \mathrm{~cm}^{3} \mathrm{~g}^{-1}\right)$, as also suggested by a decrease in the $\mathrm{H}_{2} \mathrm{O}_{2}$ decomposition rate (from $0.20 \mu \mathrm{molg}_{\mathrm{cat}}{ }^{-1} \mathrm{~min}^{-1}$ to $\left.0.06 \mu \mathrm{mol} \mathrm{g}_{\mathrm{cat}}{ }^{-1} \mathrm{~min}^{-1}\right)$. The lower TOC 


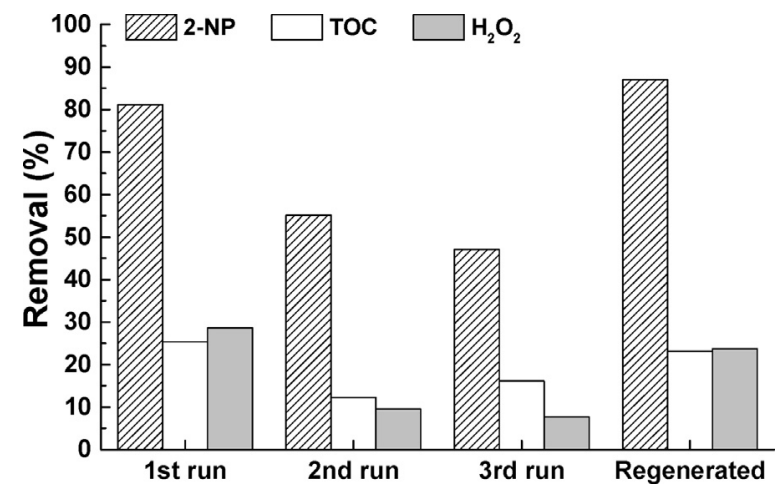

Fig. 7. 2-NP, TOC and $\mathrm{H}_{2} \mathrm{O}_{2}$ removals obtained after $24 \mathrm{~h}$ in a series of three CWPO runs, by consecutive reuse of $\mathrm{GBCM}_{300}$ and with $\mathrm{GBCM}_{300}$ regenerated after the first run.

removal value obtained when compared with the 2-NP removal, indicates the formation of the reaction by-products. From the second to the third run only slight variations were observed.

Although these observations suggest some catalyst stability after the second run, the 2-NP and TOC removals are clearly decreased when compared to those obtained when using the fresh $\mathrm{GBCM}_{300}$. Taking this into account, a simple oxidative thermal regeneration of $\mathrm{GBCM}_{300}$ recovered after the first run was carried out, considering the same conditions used for its initial activation (i.e., treatment under an air flow of $100 \mathrm{~cm}^{3} \mathrm{~min}^{-1}$ during $60 \mathrm{~min}$ at $300^{\circ} \mathrm{C}$ ). The results obtained with the regenerated $\mathrm{GBCM}_{300}$ are also shown in Fig. 7, being concluded that the catalyst activity is effectively recovered, the 2-NP and TOC removals obtained when using the regenerated $\mathrm{GBCM}_{300}$ being similar to those obtained with the fresh catalyst; furthermore, the corresponding rate of $\mathrm{H}_{2} \mathrm{O}_{2}$ decomposition is also recovered $\left(0.16 \mu \mathrm{mol} \mathrm{g}_{\mathrm{cat}}{ }^{-1} \mathrm{~min}^{-1}\right)$. The weight loss due to the thermal regeneration procedure amounts to $25 \mathrm{wt} . \%$, despite that no significant variations in porosity were observed after the regeneration treatment $\left(S_{\mathrm{BET}}=160 \mathrm{~m}^{2} \mathrm{~g}^{-1}, V_{\mathrm{Mic}}=0.04 \mathrm{~cm}^{3} \mathrm{~g}^{-1}, V_{\text {Total }}=0.09 \mathrm{~cm}^{3} \mathrm{~g}^{-1}\right)$. The slight variation in the catalytic efficiency observed between $\mathrm{GBCM}_{300}$ and regenerated $\mathrm{GBCM}_{300}$ may possibly be attributed to changes in the surface chemistry of the material promoted during the CWPO run followed by the regeneration procedure.

\section{Conclusions}

A thermally stable and non-porous carbon material, with low ash content and basic character, was produced by partial carbonization of glycerol with sulphuric acid followed by calcination under inert atmosphere.

Further thermal activation under oxidative conditions (air) at different temperatures influences both the textural and the surface chemical properties: lower temperatures (up to $200^{\circ} \mathrm{C}$ ) leading to basic materials $\left(\mathrm{pH}_{P Z C}>7.6\right)$ with a poorly developed porous structure; higher temperatures (above $300^{\circ} \mathrm{C}$ ) producing acidic materials $\left(2.6<\mathrm{pH}_{P Z C}<6.2\right)$, through incorporation of surface oxygen groups, with a significant microporous structure.

A highly active metal-free catalyst for degradation of 2-NP by CWPO was produced from glycerol selecting the appropriate thermal activation temperature $\left(300^{\circ} \mathrm{C}\right), \mathrm{GBCM}_{300}$.

Under intensified operating conditions (i.e., $T=50^{\circ} \mathrm{C}, \mathrm{pH}=3$, stoichiometric amount of $\mathrm{H}_{2} \mathrm{O}_{2}$ and a pollutant/catalyst mass ratio $=2)$ the initial removal rate of $2-\mathrm{NP}$ after $4 \mathrm{~h}$ of reaction increases 13 -fold (102.6 $\mathrm{mg} \mathrm{g}_{\text {cat }}{ }^{-1} \mathrm{~min}^{-1}$ ) when compared to the initial removal rate of 2-NP obtained in the conditions used in screening experiments $\left(7.86 \mathrm{mg} \mathrm{g}_{\mathrm{cat}}{ }^{-1} \mathrm{~min}^{-1}\right)$, making this catalyst potentially attractive for a wide range of industrial applications.

In a series of three consecutive CWPO runs performed with $\mathrm{GBCM}_{300}$, although a decrease in the 2-NP and TOC removals was observed from the first to the second run, results showed that the catalyst activity can be effectively recovered by a simple oxidative thermal regeneration.

Summarizing, active catalysts for the industrial application of the CWPO process can be produced from glycerol by tuning their surface chemistry and textural properties, thus opening a window of opportunity for value-added crude glycerol products.

\section{Acknowledgements}

Work supported by projects PTDC/AAC-AMB/110088/2009, PEst-C/EQB/LA0020/2013 and NORTE-07-0124-FEDER-0000015, co-financed by FEDER through COMPETE, QREN and ON2, and by FCT-Fundação para a Ciência e a Tecnologia.

\section{References}

[1] P.R. Gogate, A.B. Pandit, Adv. Environ. Res. 8 (2004) 501-551.

[2] C.W. Jones, Applications of Hydrogen Peroxide and Derivatives, The Royal Society of Chemistry, Cambridge, UK, 1999.

[3] J.J. Pignatello, E. Oliveros, A. MacKay, Crit. Rev. Environ. Sci. Technol. 36 (2006) $1-84$.

[4] M. Pera-Titus, V. García-Molina, M.A. Baños, J. Giménez, S. Esplugas, Appl. Catal. B: Environ. 47 (2004) 219-256.

[5] J.H. Ramirez, F.J. Maldonado-Hódar, A.F. Pérez-Cadenas, C. Moreno-Castilla, C.A. Costa, L.M. Madeira, Appl. Catal. B: Environ. 75 (2007) 312-323.

[6] J.A. Zazo, J.A. Casas, A.F. Mohedano, J.J. Rodríguez, Appl. Catal. B: Environ. 65 (2006) 261-268

[7] S. Navalon, A. Dhakshinamoorthy, M. Alvaro, H. Garcia, ChemSusChem 4 (2011) $1712-1730$

[8] H.T. Gomes, S.M. Miranda, M.J. Sampaio, A.M.T. Silva, J.L. Faria, Catal. Today 151 (2010) 153-158.

[9] R.S. Ribeiro, N.A. Fathy, A.A. Attia, A.M.T. Silva, J.L. Faria, H.T. Gomes, Chem. Eng. J. 195-196 (2012) 112-121.

[10] A. Dhaouadi, N. Adhoum, Appl. Catal. B: Environ. 97 (2010) 227-235.

[11] C.M. Domínguez, P. Ocón, A. Quintanilla, J.A. Casas, J.J. Rodriguez, Appl. Catal. B: Environ. 140-141 (2013) 663-670

[12] F. Lücking, H. Köser, M. Jank, A. Ritter, Water Res. 32 (1998) 2607-2614

[13] X. Fan, R. Burton, Y. Zhou, Open Fuels Energy Sci. J. 3 (2010) 17-22.

[14] F. Yang, M. Hanna, R. Sun, Biotechnol. Biofuels 5 (2012) 13.

[15] B.L.A. Prabhavathi Devi, K.N. Gangadhar, P.S. Sai Prasad, B. Jagannadh, R.B.N Prasad, ChemSusChem 2 (2009) 617-620.

[16] H.T. Gomes, S.M. Miranda, M.J. Sampaio, J.L. Figueiredo, A.M.T. Silva, J.L. Faria, Appl. Catal. B: Environ. 106 (2011) 390-397.

[17] R.S. Ribeiro, A.M.T. Silva, J.L. Figueiredo, J.L. Faria, H.T. Gomes, Appl. Catal. B: Environ. 140 (2013) 356-362.

[18] J.H. Ramirez, C.A. Costa, L.M. Madeira, G. Mata, M.A. Vicente, M.L. RojasCervantes, A.J. López-Peinado, R.M. Martín-Aranda, Appl. Catal. B: Environ. 71 (2007) 44-56

[19] R.S. Ribeiro, A.M.T. Silva, J.L. Figueiredo, J.L. Faria, H.T. Gomes, Carbon 62 (2013) 97-108.

[20] H.T. Gomes, B.F. Machado, A. Ribeiro, I. Moreira, M. Rosário, A.M.T. Silva, J.L. Figueiredo, J.L. Faria, J. Hazard. Mater. 159 (2008) 420-426.

[21] J.L. Figueiredo, M.F.R. Pereira, M.M.A. Freitas, J.J.M. Órfão, Carbon 37 (1999) 1379-1389.

[22] F. Rodríguez-Reinoso, Carbon 36 (1998) 159-175

[23] F. Villacañas, M.F.R. Pereira, J.J.M. Órfão, J.L. Figueiredo, J. Colloid Interface Sci. 293 (2006) 128-136.

[24] L.B. Khalil, B.S. Girgis, T.A.M. Tawfik, J. Chem. Technol. Biotechnol. 76 (2001) $1132-1140$

[25] V.P. Santos, M.F.R. Pereira, P.C.C. Faria, J.J.M. Órfão, J. Hazard. Mater. 162 (2009) 736-742.

[26] P. Serp, J.L. Figueiredo, Carbon Materials for Catalysis, John Wiley \& Sons, Inc., Hoboken, NJ, 2009. 